\title{
PENERAPAN REGIME TANGGUNG JAWAB DAN KOMPENSASI GANTI RUGI PENCEMARAN MINYAK OLEH KAPAL TANKER DI INDONESIA
}

\author{
Elly Kristiani Purwendah \\ Kandidat Doktor Fakultas Hukum Universitas Gadjah Mada Yogyakarta \\ Dosen Universitas Wijayakusuma Purwokerto \\ Email : elly_kristiani@mail.ugm.ac.id; elly_kristiani@yahoo.co.id
}

\begin{abstract}
ABSTRAK
Pencemaran minyak oleh kapal tanker merupakan risiko dari usaha minyak dalam menjalankan usahanya. Tuntutan ganti rugi pencemaran minyak oleh pemilik kapal tanker menjadi hal yang diatur secara serius oleh sistem hukum laut internasional melalui konvensi internasional tentang pertanggungjwaban sipil yang terus berkembang menjadi regime internasional tentang pertanggung jawaban dan kompensasi bagi pencemaran minyak (The International Regime on Liablity and Compensation for Oil Pollution Damage). Regime tersebut membagi tiga tingkatan kompensasi (the three tier system compensation) ganti rugi bagi pencemaran minyak sumber dari kapal tanker. Tingkatan kompensasi pertama mendasarkan pada ketentuan CLC 1969 dan IOPC Fund 1971, tingkatan kompensasi kedua mendasarkan pada ketentuan CLC 1992 dan IOPC Fund 1992, selanjutnya tingkatan kompensasi ketiga mendasarkan pada Supplementary Fund Protocol 2003. Tulisan ini bertujuan untuk mengkaji masing-masing tingkatan kompensasi serta posisi Indonesia dalam tingkatan kompensasi ganti rugi.
\end{abstract}

Key words : Regime tanggung jawab dan kompensasi ganti rugi, pencemaran minyak, kapal tanker

\section{ABSTRACT}

Oil pollution by tankers is a risk of the oil business in business. Claims for compensation for oil pollution by tanker owners become organized seriously by the system of international maritime law through an international convention on accountability for civil evolving into a regime international liability and compensation for oil pollution (The International Regime on Liablity and Compensation for Oil Pollution Damage). The regime divides three levels of compensation (the three tier system of compensation) compensation for oil pollution from tankers resources. The first compensation levels based on the provisions of the CLC 1969 and 1971 conferences were Fund, the compensation level based on the provisions of the 1992 CLC and Fund conferences were 1992, as a third level of compensation based on the Supplementary Fund Protocol of 2003. This paper aims to examine each level of compensation as well as the position of Indonesia the level of compensation for damages.

Key words: Regime of responsibility and compensation indemnity, oil pollution, tanker 


\section{Pendahuluan}

Masalah hukum pada kasus lingkungan yang menjadi perdebatan menyangkut masalah hak menggugat (ius standi), masalah pembuktian yang terkait dengan verifikasi ilmiah untuk menjelaskan hubungan kausal, asas ganti rugi, cakupan dan luas isu lingkungan untuk menetapkan jumlah ganti rugi, kriteria pemulihan lingkungan, tindak pidana lingkungan, kesaksian ahli, peranan laboratorium dan metoda analisa tercemar untuk menetapkan ada dan tidaknya pencemaran dalam artian pertimbangan hukum yang didasarkan pada perkembangan ilmu dan tehnologi disebabkan karena asas kebenaran formil yang dianut dalam sistem penuntutan ganti kerugian secara perdata.

Permasalahan pencemaran minyak dipantai menjadi sedemikian latent di Indonesia mengingat karakteristik geografis Indonesia sebagai negara kepulauan yang memiliki wilayah laut lebih luas dari daratan serta banyaknya kasus pencemaran minyak di Indonesia disebabkan beberapa wilayah pantai Indonesia secara geografis potensial pencemaran, karena karakteristik tertentu yaitu, memiliki Pelabuhan dan Badan Usaha Milik Negara untuk Pengolahan Minyak. Sebagai contoh belum lama ini di Pantai Teluk Penyu Cilacap terjadi tumpahan minyak yang sangat banyak (Gregorius Magnis Finesso, 29 Mei 2015) dan membutuhkan jangka waktu penyelesaian yang serius. Pencemaran yang terjadi berdampak serius pada Laut Cilacap dan menimbulkan korban langsung berupa pantai yang menghitam karena minyak yang secara kasat mata terihat dengan jelas. Selain itu nelayan cilacap menjadi korban yang karena sumber ikan di laut Cilacap dapat ditangkap karena dampak pencemaran. Pencemaran minyak berdampak pada kehidupan laut yang berpengaruh secara signifikan bagi masyarakat sekitar dan negara atau daerah yang bersangkutan (Zulfaidah Ariany, 2011).

Sampai saat ini masalah pencemaran belum dapat terselesaikan dengan baik bahkan pemberitaan mengenai sumber pencemar sulit untuk diakses oleh pemerintah dan masyarakat. Negara sebagai pelaksana kegiatan perlindungan lingkungan laut dan fasilitas pendukungnya seharusnya memiliki instrumen hukum untuk mengklaim ganti rugi dan restitusi bagi pelaku dan penanggung jawab usaha (Eko Widiyanto, Satya Festiani, 02 Juni 2015).

Pencemaran minyak di laut oleh kapal tanker akan menjadi perhatian serius karena pencemaran menimbulkan kerugian yang serius bagi ekologi laut dan sosiologi negara pantai. Sebuah argumentasi diberikan oleh John Maddox, pencemaran akan dapat dipecahkan dengan menghitung ongkos-ongkos yang timbul (price), pencemaran merupakan masalah ekonomi, "we can reduce pollution if we are prepared to pay it", sehingga harus dipahami bahwa masalah pencemaran adalah persoalan ekonomi, artinya berapa kemampuan kita membayarnya baik dengan menciptakan alat pencegah pencemaran anti-pollution maupun secara tidak langsung dengan membayar kerugian yang disebabkan oleh pencemaran. H.C. Combs (Sundari Rangkuti, 2000) berargumentasi bahwa economic 
changes can solve many environmental problem. Menurut dia, pencemaran dapat dikendalikan secara ekonomis melalui pengaturan hukum seperti penerapan denda, pajak pada bahan yang diproses atau limbahnya.

E.J. Mishan, dalam the cost of economic growth pada tahun enampuluhan memperkenalkan polluter pays principle (prinsip pencemar membayar) yang menyebutkan bahwa pencemar semata-mata merupakan seseorang yang berbuat pencemaran yang seharusnya dapat dihindarinya (Phillipe Sands, 2003). Pada tahun 1972 prinsip pencemar membayar dianut dan dikembangkan oleh negara-negara anggota Organisasi Kerjasama Ekonomi dan Pembangunan (Organization of Economic and Development/OECD) ((Phillipe Sands, 2003), yang menyebutkan bahwa pencemar harus menanggung beban atau biaya pencegahan dan penanggulangan pencemaran yang ditimbulkan. Sebagai instrumen ekonomi prinsip ini menggunakan internalisasi biaya dalam proses produksi yang dimaksudkan sebagai tindakan preventif kemungkinan munculnya pencemaran. Pada perkembangan selanjutnya prinsip ini mulai bergeser menjadi prinsip hukum, demikian halnya dalam sistem hukum positif Indonesia.

Prinsip ini kemudian diperluas dengan pemahaman mewajibkan kepada pelaku pencemaran untuk membayar biaya tertentu pada terjadinya kerusakan lingkungan yang disebabkan oleh aktivitasnya. Prinsip ini mewajibkan kepada pelaku untuk membayar dan bertanggungjawab terhadap setiap kerusakan lingkungan yang terjadi akibat aktivitasnya, tidak peduli apakah pelaku telah mengikuti standard lingkungan atau tidak.

Prinsip pencemar membayar ini dalam perkembangannya mengatur masalah tanggung jawab sebuah negara ke negara lain atas kerusakan lingkungan hidup yang dibuatnya. Prinsip ini lahir dari kewajiban negara untuk tidak merusak lingkungan negara lain atau teritorial di luar wilayahnya serta kewajiban orang untuk menjaga kelestarian lingkungan hidup. Prinsip pertanggungjawaban dan kewajiban pembayaran ganti kerugian pada pencemar lingkungan laut diakibatkan karena tumpahan minyak menimbulkan perlunya diatur besaran ganti kerugian yang harus dibayarkan oleh sumber pencemar. Karenanya sistem hukum internasional memberlakukan beberapa ketentuan internasional terkait batasan kerugian yang dapat diklaim oleh negara/korban pencemaran. Penulisan ini akan mengkaji pluralisme ketentuanketentuan internasional yang mengatur ganti kerugian pencemaran minyak oleh kapal tanker dan dimanakah letak posisi Indonesia dalam rezim pluralis ketentuan hukum ganti kerugian tersebut.

\section{Hasil Penelitian dan Pembahasan Prinsip ganti kerugian pencemaran minyak}

Asas tanggung jawab dalam penyelesaian lingkungan khususnya pencemaran menggunakan prinsip tanggung jawab mutlak yaitu strict liability dan absolut liability. Strict liability merupakan tanggung jawab secara langsung dan seketika, merupakan tanggung jawab yang 
bersyarat dengan pembatasan jumlah pembayaran ganti ruginya ditetapkan terlebih dahulu dalam pencemaran laut dengan cara langsung dan seketika, sedangkan absolut liability adalah tanggung jawab mutlak tak bersyarat (secara penuh dan lengkap dalam pembayaran ganti rugi). Perkembangan pengakuan asas ini di suatu negara menurut Michael Faure dan Ton Harlief dapat dilihat di dalam produk perundang-undangan dan di dalam putusan-putusan pengadilan. Diaturnya asas ini dalam peraturan perundang-undangan suatu negara seringkali disebabkan evolusi di dunia internasional terutama dengan perkembangan hukum lingkungan (M. Ramdan Andri G. W). Pada tahun 1978 pemerintah Indonesia telah meratifikasi Civil Liability Convention 1969 (N.H.T. Siahaan, 2004) dan Funds Convention 1971 dalam tata hukum nasional melalui Keputusan Presiden Nomor 18 Tahun 1978 tentang Pengesahan CLC 1969 dan Keputusan Presiden Nomor 19 Tahun 1978 tentang Pengesahan Convention for the Prevention of Pollution from ships 1973 beserta Protocol of 1978 Relating to the International Convention for the Prevention of Pollution from the Ship 1973. Dengan diratifikasinya CLC 1969 prinsip strict liability mulai dikenal dalam sistem hukum Indonesia khususnya dalam lingkup hukum lingkungan.

Konsep ini dipahami sebagai jenis kegiatan yang dapat digolongkan sebagai extrahazardous atau ultra hazaedous atau abnormally dangerous diwajibkan untuk memikul segala kerugian yang ditimbulkan meskipun yang bersangkutan telah bertindak dengan sangat hati-hati (utmost care) untuk mencegah segala bahaya dan kerugian, meskipun kerugian itu timbul tanpa adanya kesengajaan. Dalam strict liability terdapat suatu kewajiban tergugat untuk memikul tanggung jawab atas kerugian yang tidak dihubungkan dengan kesalahannya.

Kewajiban tergugat untuk memikul tanggung jawab atas kerugian ini timbul secara langsung dan seketika, begitu terdapat fakta bahwa memang telah terjadi peristiwa yang menyebabkan timbulnya kerugian (Richard A. Posner, 1986).

Asas strict liability muncul dari adanya kesadaran pada masyarakat bahwa untuk setiap perbuatan yang dilakukan baik itu oleh perseorangan maupun kelompok, maka orang atau kelompok tersebut tidak akan dapat melepaskan diri dari tanggung jawab untuk setiap kerugian yang diakibatkan oleh perbuatannya itu. Asas ini selalu dikaitkan dengan ganti rugi, konsep ultrahazardous, tort law membebankan strict liability pada aktivitas yang melibatkan bahaya dalam derajat yang tinggi yang tidak dapat dicegah oleh pihak yang telah bertindak hati-hati atau pihak yang mungkin menjadi korban. Area strict liability telah mendorong pihak yang menjalankan kegiatan yang digolongkan extrahazardous untuk membuat beberapa alternatif yang dapat mengurangi derajat bahaya (Muladi dan Dwijda Priyatno, 2010). Injurer akan melakukan tindakan pencegahan pada level yang optimal karena bila dia melakukan tindakan pencegahan dibawah level yang optimal maka akan ada total accident cost yang harus ditanggungnya.

John D. Blackburn, Elliot I. Klayman dan Martin H. Malin dengan merujuk Pasal 520, Restatement of the Law of Torts di Amerika menyatakan 
bahwa, untuk menentukan apakah suatu kegiatan termasuk kegiatan yang berbahaya (abnormally dangerous) sehingga dapat dikenakan strict liability terdapat beberapa faktor yang dapat dijadikan faktor penentu yaitu (M. Ramdan Andri G.W) :

1. Kegiatan tersebut mengandung tingkat bahaya yang tinggi bagi manusia, tanah atau benda bergerak orang lain (the capacity involves a high degree of some harm to the person, land or chattels of others);

2. Kerusakan yang diakibatkan oleh kegiatan tersebut mempunyai kemungkinan untuk menjadi besar (the harm which may result from it is likely to be great);

3. Risiko dapat tidak dihilangkan, meskipun kehati-hatian yang layak sudah diterapkan (the risk cannot be eliminated by the exercise of reasonable care);

4. Kegiatan tersebut tidak termasuk ke dalam kegiatan yang lazim (the activity is not a matter of a common usage);

5. Kegiatan itu tidak sesuai dengan tempat di mana kegiatan itu dilakukan (the activity is inappropriate to the place where it is carried on);

6. Nilai atau manfaat kegiatan tersebut bagi masyarakat (the value of activity to the community).

Dalam strict liability, seseorang bertanggung jawab kapanpun kerugian timbul. Hal ini menjelaskan keadaan bahwa:

1. Para korban dilepaskan dari beban berat untuk membuktikan adanya hubungan kausal antara kerugianny a dengan tindakan individual tergugat;
2. Para "potential polluter" akan memperhatikan baik tingkat kehati-hatiannya (level of care), maupun tingkat kegiatannya (level of activity). Dua hal ini merupakan kelebihan strict liability dari konsep kesalahan. Oleh karena sifat khasnya yang tegas dan keras, maka strict liability tidaklah dapat dikenakan pada semua kegiatan.

Menurut L.B. Curson (M. Ramdan Andri G.W) prinsip strict liability ini didasarkan pada alasanalasan sebagai berikut:

a. Sangat esensial untuk menjamin dipatuhinya peraturan-peraturan penting tertentu yang diperlukan untuk kesejahteraan sosial;

b. Pembuktian adanya mens rea akan menjadi sangat sulit untuk pelanggaran-pelanggaran yang berhubungan dengan kesejahteraan sosial itu;

c. Tingginya tingkat bahaya sosial yang ditimbulkan oleh perbuatan yang bersangkutan.

Ganti rugi dalam strict liability biasanya dikaitkan dengan sistem plafond atau ceiling (batas maksimal tanggung jawab). Pihak yang bertanggung jawab hanya dibebankan sampai dengan batas tertentu. Indonesia menganut paham plafond atau ceiling dalam stricy liability karena dalam penjelasan Pasal 35 ayat (1) Undang-undang Nomor 23 Tahun 1997 tentang Pengelolaan Lingkungan Hidup (UUPLH) maupun dalam penjelasan Pasal 88 Undang-undang Nomor 32 Tahun 2009 tentang Perlindungan dan Pengelolaan Lingkungan Hidup (UUPPLH) dijelaskan bahwa besarnya nilai ganti rugi yang dapat dibebankan terhadap pencemar atau 
perusak lingkungan hidup dapat ditetapkan sampai batas tertentu.

Pengertian sampai batas tertentu menurut peraturan perundang-undangan yang berlaku, ditentukan kewajiban adanya asuransi bagi usaha dan/atau kegiatan yang bersangkutan atau telah tersedia dana lingkungan hidup. Prinsip ini kemudian diperluas dengan pemahaman mewajibkan kepada pelaku pencemaran untuk membayar biaya tertentu pada terjadinya kerusakan lingkungan yang disebabkan oleh aktivitasnya. Prinsip ini mewajibkan kepada pelaku untuk membayar dan bertanggungjawab terhadap setiap kerusakan lingkungan yang terjadi akibat aktivitasnya, tidak peduli apakah pelaku telah mengikuti standard lingkungan atau tidak. Prinsip pencemar membayar ini dalam perkembangannya mengatur masalah tanggung jawab sebuah negara ke negara lain atas kerusakan lingkungan hidup yang dibuatnya. Prinsip ini lahir dari kewajiban negara untuk tidak merusak lingkungan negara lain atau teritorial di luar wilayahnya serta kewajiban orang untuk menjaga kelestarian lingkungan hidup.

Selain asas polluter pays principle, berlaku pula asas tanggung jawab mutlak (strict liability) dalam penyelesaian sengketa lingkungan khususnya pencemaran laut. Asas tanggung jawab mutlak yang bersyarat dengan pembatasan jumlah pembayaran ganti ruginya yang ditetapkan terlebih dahulu dalam pencemaran laut secara langsung dan seketika. Prinsip strict liability yang dianut dalam pencemaran laut yang disebabkan oleh minyak, mewajibkan setiap pelaku wajib membayar ganti rugi pada negara pantai timbul seketika pada saat tumpahnya minyak dilaut dan timbulnya kerugian tanpa mempersoalkan bersalah atau tidaknya kapal tanki yang bersangkutan, sebagaimana terdapat dalam Pasal 3 (1) International Convention on Civil Liability for Oil Pollution Damage 1969 (CLC 1969) yang berbunyi (Komar Kantaatmadja, 1981) :

"...the owner of a ship a serious occurrences at the time of incident or where the incident consist of a serious occurances at the time of the first such occurance, shall be liable for any pollution damage by oil which has escaped or been discharged from the ship as a result of the incident".

Prinsip ini diakomodir dalam sistem hukum Indonesia sebagaimana disebutkan dalam Pasal 88, UU Nomor 32 Tahun 2009 tentang Perlindungan dan Pengelolaan Lingkungan Hidup yang menyatakan bahwa :

"Setiap orang yang tindakannya, usahanya, dan/atau kegiatannya menggunakan B3, menghasilkan dan/atau mengelola limbah B3, dan/atau yang menimbulkan ancaman serius terhadap lingkungan hidup bertanggung jawab mutlak atas kerugian yang terjadi tanpa perlu pembuktian unsur kesalahan".

Pada Penjelasan Pasal 88 UU Nomor 32 Tahun 2009 dijelaskan bahwa yang dimaksud dengan "bertanggung jawab mutlak", atau strict liability adalah unsur kesalahan tidak perlu dibuktikan oleh pihak penggugat sebagai dasar pembayaran ganti rugi. Ketentuan ayat ini sebagai lex specialis dalam gugatan tentang perbuatan melawan hukum pada umumnya. Besarnya nilai ganti rugi yang dapat dibebankan terhadap 
pencemar atau perusak lingkungan hidup menurut Pasal ini dapat ditetapkan sampai batas tertentu (http://www.amsa.gov.an).

Sistem tanggung jawab strict liability (James E. Krier) mempunyai kekhususan karena proses hukum penuntutan ganti kerugian menjadi lebih sederhana dan relatif lebih pendek. Hal ini membuat proses klaim tuntutan ganti rugi menjadi lebih mudah daripada proses klaim tuntutan ganti rugi pada umumnya. Namun luas lingkup ganti kerugian yang dimungkinkan menjadi terbatas karena segi lain dari tanggung jawab mutlak (strict liability) adalah adanya suatu batas tertinggi plafond/ceiling dari jumlah ganti rugi (http://www.imo.org), dapat disimpulkan, bahwa karena sifat dari tanggung jawab mutlak (strict liability) yang khusus yaitu mengecualikan unsur umum ganti rugi berupa adanya unsur kesalahan (pengertian yang luas) si pelaku, maka kepadanya dilekatkan hal-hal yang harus dilihat sebagai satu kelompok (parcel) dengan kerugiannya yaitu adanya limitation of liability yang membuatnya menjadi suatu sistem ganti rugi mutlak yang terbatas jumlahnya dan no liability dalam hal berlakunya pengecualian terhadap tanggung jawab mutlak (strict liability) ini. Dengan demikian dapat dipahami apa yang dikemukakan oleh Goldie (1969) yaitu bahwa :

"The strictness of the liability to be imposed should depend upon the type of acticity causing the harm, the type of activity harmed or through which an individual is harmed, and the juxtaposition of the operator and the injured".
Ganti rugi dalam pencemaran laut yang disebabkan oleh minyak dari kapal tanker menurut hukum internasional dapat dilakukan dengan beberapa hal yaitu (Pieter Batti, 1995) :

1. Berdasarkan $\quad$ CLC 1969 menentukan tanggung jawab atau kontribusi dari pemilik kapal terhadap pencemaran yang datangnya dari kapal. Batas tanggung jawab ganti rugi US\$ 20 juta dan hanya berlaku pada kapal tanker yang mengangkut muatan minyak persistent oil.

2. The Fund Convention membentuk IOCP Fund untuk memberikan kompensasi ganti rugi kerusakan akibat pencemaran bila dana dari CLC Convention tidak mencukupi. The Fund Convention dibiayai oleh anggota (Negara) dari Fund Convention melalui perhitungan jumlah minyak (persistent oil) yang diterima (oil received). Batas tanggung jawab dalam hal pemberian ganti rugi dari the Fund Convention sampai dengan US\$ 84 juta sudah termasuk yang dibayarkan oleh CLC Convention.

Fund Convention memungut uang kontribusi dari para anggotanya, juga menawarkan beberapa bantuan yang menyangkut masalah pencegahan dan penanggulangan pencemaran yang dapat dimanfaatkan oleh para anggota antara lain memberikan bantuan pada anggota untuk memanfaatkan fasilitas administrasi dan perkantoran Fund Convention dan membantu melakukan penyelesaian klaim, menyediakan material dan bantuan pelayanan untuk mengurangi kerusakan akibat pencemaran karena kecelakaan, dan IOPC berperan sebagai pembayar 
kompensasi dan menyediakan "credit facilities" yang akan digunakan untuk menanggulangi pencemaran akibat kecelakaan.

Peranan dari the CLC Convention dan the Fund Convention terbatas pada kecelakaan yang mengakibatkan pencemaran dari persistent oil saja, sedangkan light diesel oil, gasoline dan sebagainya tidak termasuk dalam kedua konvensi tersebut. Kerusakan akibat pencemaran yang dapat ditanggung oleh konvensi tersebut hanya terbatas pada biaya usaha pencegahan yang dilakukan pada waktu terjadi pencemaran. Kerugian ekonomi (economic loses) dan kerusakan lingkungan (environmental losses) yang berhubungan dengan biaya rehabilitasi dan pembersihan.

\section{Rezim Kompensasi Pencemaran Minyak di Laut oleh Kapal Tanker Rezim Lama (The 1969 CLC dan 1971 Fund)}

Tiga tingkatan dalam rezim kompensasi ini bermula dari rezim lama yaitu pada masa awal berlakunya The 1969 CLC dan 1971 IOPC Fund Regime. Kedua konvensi ini menyediakan kompensasi tingkat pertama dan mewajibkan pemilik kapal bertanggungjawab untuk kerusakan pencemaran minyak yang ditimbulkan. Kerusakan polusi merujuk pada kerugian atau kerusakan yang disebabkan dari pembuangan kapal yang mengakibatkan kontaminasi seiring dengan penurunan lingkungan dan biaya-biaya pencegahan pencemaran (Article 1(6), 1992 CLC).

Pada umumnya klaim dapat diajukan untuk kerusakan property, kerugian konsekuensial dan kerugian ekonomi murni. kedua ketentuan konvensi ini memiliki esensi yang sama. The CLC 1969 dalam hal aplikasi secara geografis lebih sempit, hanya berlaku untuk kerusakan pencemaran yang diderita di wilayah laut teritorial negara anggota. Kerusakan pencemaran hanya pada zone ekonomi ekslusif (ZEE) atau daerah yang setara dengan negara anggota tidak di cover oleh CLC 1969 tersebut (United Nations Conference on Trade and Development).

CLC berlaku untuk kerusakan pencemaran yang disebabkan oleh "persistent oil" yang tumpah atau dibuang dari kapal yang membawa minyak dalam jumlah besar sebagai kargo. Konvensi ini diberlakukan hanya pada kerusakan yang disebabkan oleh tumpahan muatan minyak dari kapal tangki dan tidak termasuk tumpahan minyak yang bukan muatan atau usaha pencegahan murni yang dilakukan dimana tidak ada sama sekali Minyak yang tumpah dari kapal tangki. Konvensi ini juga hanya berlaku pada kapal yang mengangkut minyak sebagai muatan yakni kapal tangki pengangkut minyak. Tumpahan (Spills) dari kapal tangki dalam pelayaran "Ballast Condition" dan spills dari bunker oil atau kapal selain kapal tangki tidak termasuk dalam konvensi ini, Kerusakan yang disebabkan oleh "Non-presistent Oil" seperti gasoline,kerosene, light diesel oil, dan lain sebagainya, juga tidak termasuk dalam CLC Convention. Pertanggungjawaban yang ketat diberlakukan bagi pemilik terhadap pencemaran kapal, yang berarti bahwa pemilik akan bertanggung jawab terlepas dari unsur kesalahan, bahkan tanpa adanya unsur kelalaian. Pada umumnya kewajiban timbul, apabila penggugat mampu membuktikan bahwa minyak yang 
mencemari berasal dari kapal pemilik kapal yang bersangkutan. Kerusakan pencemaran yang disebabkan tumpahan minyak dari satu kapal atau lebih dan tidak beralasan untuk memisahkan kerusakan, kedua pemilik kapal terdaftar akan bertanggung jawab secara tanggung renteng (United Nations Conference on Trade and Development). Limitatif dari CLC pada awalnya dinyatakan dalam france emas yang bernilai 133 SDRs per ton subject sampai nilai maksimum global 14 juta SDRs (R. Bhanu Krishna Kiran, October-Desember 2010). Jumlah maksimum kompensasi yang dibayar oleh pemilik kapal dibawah CLC 1969 adalah setara dengan 19 juta US\$. CLC 1969 mempergunakan nilai emas (poincare france) berdasarkan atas nilai mata uang negara lainnya. Pada Protocol 1976 mulai diperkenalkan bentuk unit of account yang didasarkan atas Special Drawing Rights (SDR) seperti yang dipergunakan oleh International Monetary Fund (IMF) (IMO, Protocol 1976).

Protokol ini dimaksudkan untuk mengatasi perkembangan yang terjadi serta mengantisipasi penjabaran nilai poin ganti rugi yang terjadi pada CLC 1969. Pasal 2 dalam Protokol CLC 1976 menyebutkan bahwa batas ganti rugi adalah 133 unit of account untuk setiap ton dari tonase kapal. Dengan jumlah keseluruhan tidak melebihi 14 juta units of account. Selanjutnya Protokol 1984 diadopsi pada tanggal 25 Mei 1984. Dikeluarkannya ketentuanketentuan dalam Protokol 1984 oleh IMO dimaksudkan untuk menambah batas tanggung jawab. Protokol ini tidak dapat diberlakukan karena tidak mencapai persyaratan ratifikasi sebagaimana disyaratkan oleh protokol. Faktor utama tidak dapat diberlakukannya protokol ini karena keengganan negara-negara pengimpor minyak termasuk Amerika Serikat untuk meratifikasi. Amerika Serikat cenderung menerapkan sistem tanggung jawab yang tidak terbatas (a system of unlimited liability). Pada tanggal 18 Desember 1971 IMCO berhasil merumuskan International Convention on the Estabblishment of an International Fund for Oil Pollution Damage, 1971 (Fund Convention 1971), mulai berlaku pada tanggal 16 Oktober $1978 \quad$ (Article 2 (2) Protocol1976).

Fund Convention merupakan suplement CLC 1969 dan akan membayar ganti rugi pencemaran lingkungan laut apabila jumlah ganti rugi yang akan dibayarkan berdasarkan CLC 1969 tidak mencukupi (www.imo.org). Tujuan diciptakannya konvensi ini adalah (www.amsa .gov.an) :

(1) to provide compensation for oil pollution damage to extend that the protection aff orded by the 1996 Civil Liability Convention is in adequate;

(2) to give relief to shipowners in respect of the additional financial burden imposed on them by the 1969 Civil Liability Convention, such relief being subject to conditions designed to ensure complience with safety at sea and other conventions;

(3) to give effect to the related purpose set out in the Convention.

Besarnya ganti rugi yang dapat dibayar berdasarkan Pasal 4 ayat (4) dan (6) Fund Convention 1971 adalah tidak melebihi 450 france. Jumlah ini dapat disesuaikan berdasarkan 
"perubahan nilai mata uang" namun tidak melebihi 900 juta france. Fund Convention 1971 menetapkan jenis minyak yang dapat dipertanggungjawabkan adalah jenis crude oil dan fuel oil (www.imo.org). Protokol Fund Convention 1976 diadopsi pada tanggal 9 November 1976 dan mulai berlaku efektif pada tanggal $22 \quad$ November 1994. Perubahan yang terdapat pada Protokol Fund Convention 1976 selain perubahan nilai ganti rugi menjadi Special Drawing Right (SDR), perubahan lainnya adalah (Fund Convention 1971, Article 1 (3) :

(a) 450 juta france diganti dengan 30 juta units of account atau 450 juta monetary units;

(b) 900 juta france diganti dengan 60 juta unts of account atau 900 juta monetary units.

\section{Rezim Baru (The 1992 CLC dan 1992 IOPC Fund Regime)}

Berdasarkan konvensi pendahulu mereka, kedua konvensi ini masih mempertahankan sistem kewajiban kompensasi bertingkat dengan kewajiban terbatas dari pemilik kapal bergantung dari tonase dan kompensasi tambahan yang tersedia dari kompensasi dana internasional hingga jumlah maksimum keseluruhan per insiden. CLC 1992 mengatur kewajiban pemilik kapal untuk kerusakan minyak. Konvensi ini berdasarkan pada prinsip tanggung jawab mutlak untuk pemilik kapal dan menciptakan sistem asuransi wajib. Pemilik kapal berhak membatasi jumlah ganti rugi berkaitan dengan tonase kapal. Fund 1992 memberikan kompensasi tambahan kepada para korban ketika kompensasi yang diberikan CLC 1992 tidak memadai. CLC 1992 berlaku untuk kerusakan pencemaran termasuk laut territorial dan zona ekonomi eklusif (ZEE) atau negara anggota konvensi. CLC 1992 berlaku untuk kapal-kapal pembawa minyak dalam jumlah besar umumnya tanker, tumpahan minyak dari kapal bunker selain tanker.

Batas ganti rugi menurut Pasal 6 Protocol CLC 1992, adalah sebagai berikut (http://www.imo.org) :

1. Kapal tidak melebihi 5.000 gross tonage, batas tanggung jawabnya adalah 3 juta SDR (setara dengan US\$ 4,1 juta). Untuk jenis kapal yang beratnya 5.000 sampai 140.000 gross tonnage, batas tanggung jawabnya mencapai 3 juta SDR ditambah dengan perkalian sebesar 420 SDR (setara dengan US\$ 567) untuk setiap tambahan tonase;

2. Kapal diatas 140.000 gross tonnage, batas tanggung jawabnya adalah 59, 7 juta SDR (setara dengan US\$ 80 juta).

Klaim berdasarkan CLC 1992 hanya dapat dilakukan kepada pemilik kapal terdaftar, keadaan ini tidak menghalangi korban untuk mengklaim kompensasi di luar konvensi tersebut selain kepada pemilik tanker. CLC 1992 melarang klaim terhadap pegawai atau agen dari pemilik, pilot, penyewa, manager atau operator kapal, atau orang yang melakukan operasi penyelamatan atau mengambil langkah-langkah pencegahan. Kompensasi yang dibayarkan oleh Fund 1992 sehubungan dengan insiden terbatas untuk jumlah keseluruhan dari 203 juta SDR (US\$ 292.000.000 atau 249.800.000€) termasuk jumlah yang sebenarnya dibayar oleh pemilik kapal (atau asuransinya) dibawah CLC 1992. Fund 1992 dapat 
membayar kompensasi kepada penggugat hanya sejauh klaimnya dibenarkan dan memenuhi kriteria yang ditetapkan. Untuk tujuan ini, penuntut perlu membuktikan klaimnya dengan membuat catatan, faktur, kwitansi dan dokumen lainnya untuk mendukung klaim tersebut.

Insiden The Prestise 2002, menyerukan review baru dari jumlah kompensasi, karena menjadi jelas klaim diterima akibat insiden akan melebihi jumlah maksimum yang tersedia di bawah CLC 1992 dan Fund 1992. Sesuai dengan The Supplementary Fund Protocol 2003, diperkenalkan ketiga tingkat opsional kompensasi untuk negara peserta CLC 1992 dan Fund 1992 (The 2003 Supplementary Protocol). Protokol ini mulai berlaku pada tanggal 3 Maret 2005, International Oil Pollution Compensation Fund (The Supplementary IOPC Fund) menyediakan kompensasi tambahan untuk klaim di bawah IOPC Fund 1992 sampai sejumlah maksimum
750 juta SDR per kejadian (setara dengan sekitar US\$1157,2 juta).

Belum pernah ada insiden yang diperlukan kompensasi dari tambahan Supplementary IOPC Fund. Supplementary IOPC Fund menjadi tingkat ketiga kompensasi dengan memberi perlindungan bagi negara anggota anggota CLC 1992 dan Fund 1992 dengan cara meratifikasi atau mengaksesi The Supplementary Fund Protocol 2003. Supplementary IOPC Fund hanya akan memberikan kompensasi untuk kerusakan pencemaran minyak yang diderita negara kontrak diakui oleh IOPC Fund 1992 tetapi melebihi batas yang relevan menurut CLC 1992. Jumlah total kompensasi yang tersedia dari Supplementary IOPC Fund terbatas untuk 750 juta SDR jumlah keseluruhan 203 juta SDR. manfaat yang signifikan dari Supplementary IOPC Fund memungkinkan semua penuntut menerima $\quad 100 \%$ kompensasi.

Tabel 1. Jumlah maksimum kompensasi bagi insiden pencemaran (nilai dinyatakan dalam juta SDR) berlakunya instrument hukum internasional dan jumlah negara peserta

\begin{tabular}{|l|c|c|c|c|}
\hline $\begin{array}{l}\text { Ukuran } \\
\text { tanker } \\
\text { (gt) }\end{array}$ & $\begin{array}{l}\text { Amandemen } \\
\text { CLC 1969 }\end{array}$ & $\begin{array}{l}\text { CLC 1992 } \\
\text { (setelah 2003) }\end{array}$ & $\begin{array}{l}\text { Fund 1992 } \\
\text { (setelah 2003) }\end{array}$ & $\begin{array}{l}\text { Supplementary } \\
\text { Fund 2003 } \\
\text { Protocol**** }\end{array}$ \\
\hline 5.000 & 0.665 & 4.510 & 203 & 750 \\
\hline 10.000 & 1.33 & 7.665 & 203 & 750 \\
\hline 50.000 & 6.65 & 32.905 & 203 & 750 \\
\hline 100.000 & 13.3 & 64.455 & 203 & 750 \\
\hline 140.000 & 14 & 89.695 & 203 & 750 \\
\hline 150.000 & 14 & 89.770 & 203 & 2703 \\
\hline 200.000 & 14 & 89.770 & 203 & $\mathbf{2 7 *}$ \\
\hline $\begin{array}{l}\text { Negara } \\
\text { peserta }\end{array}$ & $\mathbf{3 7 *}$ & $\mathbf{1 2 4 * *}$ & $\mathbf{1 0 5 * *}$ & \\
\hline
\end{tabular}


* mencakup beberapa negara anggota CLC 1992 dan Fund 1992 serta beberapa negara yang juga pihak dalam CLC 1992 tidakdalam Fund 1992. Termasuk negara yang mengecam konvensi efektif 25 Mei 2012.

**CLC 1992 dan Fund 1992 mulai berlaku pada tahun 2012 diikuti empat negara yang menyetujui. Supplementary Fund 2003 mulai berlaku di tahun 2012 untuk satu negara.

***jumlah maximum termasuk yang dibayarkan dibawah CLC 1992

****jumlah maximum termassuk yang dibayarkan dibawah CLC 1992 dan

Fund 1992.

gt $=$ gross tonnage

SDR (SDR : Special Drawing Right) = Special Drawing Right. Jumlah yang relevan dari SDR didefinisikan oleh International Monetary Fund. Relevan dengan rate pertukaran pada 3 Januari 2012 adalah 1 SDR $=1.542 .930$ US\$.

Sumber : Information on Contracting States based on IMO (www.imo.org); SDR exchange rate based on (www.imf.org)

\section{Skema 1. Rezim Kompensasi, Tiga Tingkatan Kompensasi yang Ditetapkan oleh Konvensi Internasional}

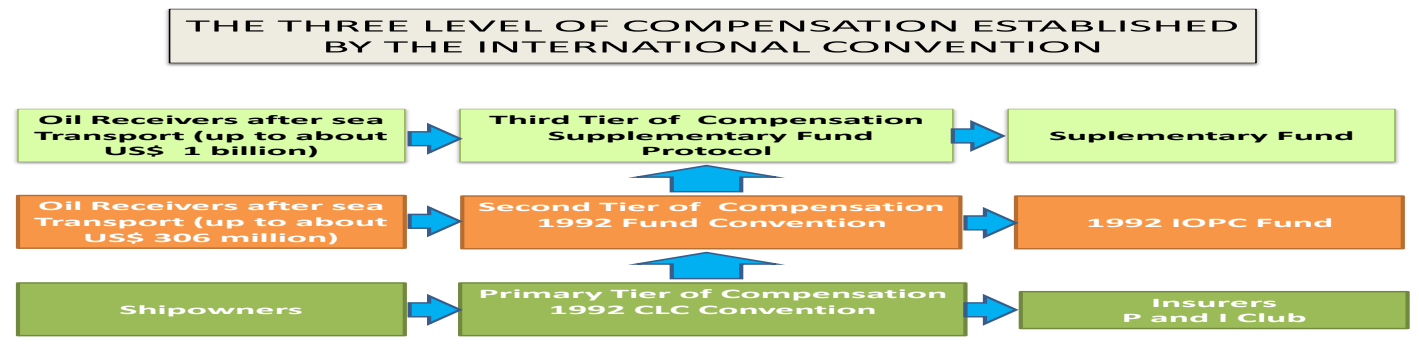

CLC memerlukan instrumen untuk diberlakukan melalui sebuah pertanggungan wajib (compulsory insurance) yang mewajibkan pemilik dari kapal yang membawa lebih dari 2.000 ton minyak (baik dalam bulk maupun dalam cargo) wajib menutup asuransi atau bentuk pertanggungan lain yang jumlahnya sesuai dengan batas pertanggungjawaban pembayaran ganti ruginya (CLC 1969. Article VIII (1)), bukan berarti tidak adanya pertanggungjawaban pemilik kapal berdasarkan konvensi apabila pemilik kapal berdasarkan konvensi mengangkut minyak kurang dari 2.000 ton (CLC 1969. Article VIII (1). Dalam hal demikian pemilik dibebaskan dari kewajiban untuk menutup pertanggungan wajibnya. Dalam ketentuan pertanggungan wajib ini, setiap kapal tanker diwajibkan untuk membawa sertifikat dalam bentuk yang sesuai dengan ketentuan dimana kapal diregistrasikan yang menyatakan tentang adanya dan masih berlakunya pertanggungjawaban wajib. Tanpa sertifikat, negara registrasi tidak dibenarkan untuk mengijinkan kapal tersebut berlayar. Sertifikat ini akan diterima dan dihargai berdasarkan konvensi oleh setiap negara peserta. Konvensi menentukan bahwa klaim ganti rugi dapat diajukan langsung kepada 
pihak penanggung atau pihak lain yang memberikan jaminan. Penanggung menggunakan asas strict liability meskipun ada kemungkinan terdapatnya fakta yang mengecualikan asas tersebut.

Asuransi yang dibentuk sebagai pelaksanaan CLC dikenal sebagai voluntary industry schemes yang disebut TOVALOP (the Tanker Owner's Voluntary Agreement Concerning Liability for Oil Pollution) dan CRISTAL (Contract Regarding an Interim Supplement to Tanker Liability for Oil Pollution) yang menyediakan kompensasi ganti rugi kerusakan akibat pencemaran minyak. Kedua skema ini dibentuk bersamaan dengan konvensi internasional, tujuan dari kedua skema industri ini adalah untuk menyelesaikan kompensasi ganti rugi yang sebanding dengan yang diberikan oleh CLC dan Fund Convention untuk negara yang belum meratifikasi kedua konvensi tersebut (International Oil Polution Compensation Funds, 92 Fund/A.ES.10/13). TOVALOP dan CRISTAL dimaksudkan untuk penyelesaian secara internal dan akan tetap berlaku sampai konvensi internasional berlaku secara global.

Bersamaan dengan tanggung jawab yang berat dari pemilik kapal tanker untuk membayar ganti rugi dalam hal tumpahnya minyak, Konvensi Brussel 1969 tentang pertanggung jawaban Perdata telah menentukan batas tertinggi dari tanggung jawab pemilik tanker. Sebagai pelaksanaan menjelang diciptakannya Funds Conventions, diciptakan TOVALOP dengan tujuan (Pieter Batti):

1. to encourage immediate remedial action by participating tanker owners in the event of discharge of oil;

2. to assure financial capability of participating tanker owners to fulfil their obligations under tovalop through insurance coverage;

3. to avoid jurisdictional problems under existing maritime law and practice;

4. to place on tanker owners the burden of disproving negligence;

5. the provide a national government withmachinery for making valid claims not with standing the fact that such government might not, under international or local law, have a legal obligation to remove oil discharge from a tanker or a legal right to recover removal expenses.

Sifat dari TOVALOP sebagai suatu lembaga pertanggungan pencemaran minyak swasta (private) (The International Tanker Owners Pollution Federation Ltd) dan memberikan ganti rugi atas dasar perjanjian pertanggungan dan premi yang diterimanya. Bentuk asuransi ini akan menanggung kerugian bagi pesertanya karena tumpahan minyak sebanyak US\$100 untuk setiap gross ton bobot kapal yang didaftarkan (gross registered ton) dengan jumlah tertinggi sebanyak US\$ 10.000.000. Setelah 1 Juni 1981 jumlah ini akan meningkat menjadi penanggungan kerugian US\$ 147 untuk tiap gross tonnage bobot kapal dengan jumlah tertinggi sebanyak US\$ 16.800 .000 . Hal-hal yang merupakan karakteristik dari lembaga pertanggungan ganti rugi pencemaran minyak TOVALOP adalah sebagai berikut :

1. TOVALOP tidak memperhatikan masalah apakah peristiwa terjadi di satu wilayah negara tertentu, 
baik peserta maupun bukan peserta dari Konvensi tentang Civil Liability for Oil Pollution Damage, yang diperhatikan hanya keadaan tumpahnya minyak dan timbulnya kerugian karena tercemarnya pantai suatu negara;

2. Bahwa tumpahnya minyak disebabkan karena kesalahan atau kurang hati-hatinya pihak kapal tanker;

3. Bahwa klaim akan diselesaikan oleh badan asuransi dari Tanker Owners Pollution Federation Ltd, dengan tidak menutup adanya kemungkinan penggunaan lembaga arbitrase;

4. Bahwa klaim hanya dapat diajukan oleh negara nasional saja dan bukan oleh pihak-pihakpihak privat;

5. Ganti rugi pada mulanya hanya terbatas pada kerugian privat yang merupakan direct cost, immediate preventive measures dan direct damages by psysical contamination, baru kemudian ditambahkan dengan ganti rugi yang diakibatkan oleh pencemaran termasuk tindakantindakan yang dilakukan untuk mengurangi atau mengalihkan kemungkinan-kemungkinan terjadinya kerusakan. Ganti rugi berdasarkan TOVALOP ini mengecualikan consequential dan ecological damages.

CRISTAL (TOVALOP adalah suatu Limited Company yang berkedudukan di London dengan nama The International Tanker Owners Pollution Federation Limited) merupakan suatu bentuk pertanggungan sukarela (voluntary) berikutnya setelah TOVALOP. Bentuk coverage ini merupakan asuransi yang ditutup oleh para pemilik minyak yang diangkut oleh tanker yang telah mengikuti TOVALOP coverage. Coverage ini akan berlaku dalam hal :

1. Minyak yang tumpah adalah milik dari perusahaan yang merupakan anggota dari CRISTAL;

2. Kapal yang mengangkut dipertanggung jawabkan berdasarkan TOVALOP;

3. Kerugian yang timbul diberikan ganti rugi berdasarkan Konvensi Brussel 1969 tentang Civil Liability for Oil Pollution Damage. Pertanggungan CRISTAL dimaksudkan untuk memberikan tambahan (supplement) kepada jumlah ganti rugi yang tersedia oleh pertanggungan lainnya. Adapun jumlah dari coverage CRISTAL adalah sampai US\$30.000.000, setelah 1 Juni 1981 menjadi US\$ 36.000 .000 dengan kemungkinan bagi para anggota untuk meningkatkan jumlah ini sampai dengan US\$ 72.000.000 jika ternyata jumlah sebelumnya dianggap tidak mencukupi. Luas lingkup pollution damage seperti yang dimaksud dalam CRISTAL adalah lebih luas dari pollution damagenya TOVALOP disebabkan karena :

1. Tidak dengan tegas menutup kemungkinan ganti rugi ekologis;

2. Tidak hanya berlaku terhadap kerusakan pantai, sedangkan pembatasannya sepanjang kerugian ekologis ini tidak bersifat remote dan speculative (Pada 1 januari 1971, perusahaan-perusahaan pemilik minyak yang tergabung dalam Oil Companies Institute for Marine Pollution, Compensation Ltd., sebuah Badan Hukum Bermuda mendirikan CRISTAL ). 
Kesamaan kedua jenis tuntutan ini adalah, bahwa recovery hanya dapat dituntutkan dalam masa satu tahun saja. Klaim TOVALOP disampaikan kepada pemilik tanker dengan tembusan kepada Federation. Dalam Clause IV (E) tentang Insurance coverage dari ketentuan Kontrak CRISTAL ("...any loss or damage which is remote or speculative, or which does notresult directly from the escape or discharge of oil".) yang lain dari pengaturan yang diberikan oleh TOVALOP menghendaki bahwa pihak yang menuntut ganti rugi harus :

1. Compensate any person who sustained pollution damage (excluding the owners of the tanker) to the extent that such person has been unable, after having taken all reasonable steps to pursue the remedies available to him, to obtain full compensation for said pollution damage from :

(a). the owner of the tanker, and;

(b). any other person or vessel liable there for, and;

(c). any other source of compensation available under convention, law, or regulation, including but not limited to a fund established and maintained by means of assessments against Oil Companies.

2. Compensate the owner for the Cost of Preventive Measures taken by him in respect of such escape or discharge to the extent that the owner has been unable after having taken all reasonable steps to pursue the remedies available to him, to obtain full compensation there for from :

(b). any other person or vessel liable there for, and; (c). any other source of compensation available under convention, law or regulation, including but not limited to a fund established and maintained by means of assessments against Oil Companies.

Mengingat sifat TOVALOP sebagai pelengkap dari CLC, maka TOVALOP juga mempunyai luas lingkup berlakunya bagi negaranegara peserta dari CLC, sedangkan CRISTAL tidak terbatas berlakunya pada negara-negara peserta dari CLC. Dalam hubungannya dengan asas strict liability berbeda dengan CLC, Fund Convention, dan Kontrak CRISTAL, maka ketentuan TOVALOP baru menganut asas ini setelah Juni 1978.

The voluntary scheme disempurnakan pada tahun 1987, TOVALOP ditambah supplement dengan nama Standing Agreement. TOVALOP Supplement hanya berlaku untuk kecelakaan tanker yang mengangkut muatan minyak yang dimiliki anggota CRISTAL. Untuk semua kasus yang lain, hanya TOVALOP Standing Agreement yang digunakan. Seperti halnya kewajiban ganti rugi pemilik kapal dibawah CLC Convention, TOVALOP Schemes ditanggung oleh asuransi pemilik kapal P \& I Club untuk kapal tanker. CRISTAL Schemes dibiayai oleh pemilik muatan meliputi hampir seluruh muatan minyak yang diangkut melalui laut (M. Sumampouw, 1980).

Persetujuan yang disempurnakan sudah digunakan secara global dengan tidak melihat apakah CLC Convention dan Fund Convention berlaku untuk kecelakaan yang terjadi. Karena itu TOVALOP dan CRISTAL diaplikasikan hampir 
sama dengan CLC Convention dan Fund Convention. TOVALOP dan CRISTAL hanya menanggung pure threat situations, yaitu hanya sebagai tindakan preventif saja. TOVALOP Standing Agreement digunakan untuk tumpahan minyak berasal dari tankers in ballast.

Batas kompensasi dibawah TOVALOP Supplement adalah 3,5 juta untuk tanker dengan ukuran tidak lebih dari 5.000 gross tonnage, batas limit bertambah 493 US\$ setiap tambahan per ton dengan maksimum pembayaran 70 juta US\$ untuk kapal diatas 140.000 gross tons. Batas limit ini hanya berlaku untuk muatan yang dimiliki anggota CRISTAL. TOVALOP Standing Agreement tidak digunakan apabila tanggungjawab (liability) lain di bawah CLC Convention yang menanggung.

Apabila batas limit dari TOVALOP Supplement terlampaui, klaim ke CRISTAL hanya dapat dilakukan apabila jumlah keseluruhan dari biaya kerusakan melebihi kompensasi yang tersedia di bawah Fund Convention. Maksimum kompensasi dibayar dibawah CRISTAL termasuk jumlah yang tersedia di bawah TOVALOP Supplement atau dibawah CLC Convention dan Fund Convention adalah 36 juta US\$ untuk tanker ukuran sampai dengan 5.000 tons. Kapal yang melebihi maksimum 135 juta US\$ untuk kapal ukuran melebihi 140.000 tons. Coverage yang lain selain TOVALOP dan CRISTAL berdasarkan pada Protection and Indemnity Insurance didasarkan sepenuhnya atas premi yang dibayar oleh pihak pemilik tanker untuk menutup kemungkinan timbulnya kerugian karena pencemaran minyak yang tumpah dari tankernya.
Ganti rugi yang dapat dituntut berdasarkan Protection and Indemnity Clause ini hanya terbatas pada tanggung jawab berdasarkan hukum yang telah ada sebelumnya baik berdasarkan CLC, TOVALOP atau CRISTAL. Umumnya pertanggungan untuk ganti rugi yang diakibatkan karena pencemaran minyak ini bentuknya adalah dengan menyisipkan klausula yang berupa jumlah pertanggungan berdasarkan Konvensi tentang CLC, tanggung jawab berdasarkan TOVALOP dan/atau CRISTAL dalam perjanjian Asuransi Protection and Indemnity.

Dalam hal pencemaran minyak di laut, ketentuan-ketentuan tanggung jawab yang terdapat pada Konvensi-konvensi yang bersangkutan merupakan ketentuanketentuan yang telah disetujui untuk diberlakukan dan mengikat pihakpihak yang bersangkutan. Mengingat sifat khusus pengangkutan minyak di laut serta bahaya risiko finansial yang besar maka pengaturan yang mengaturnya bersifat sui generis. Berdasarkan pemikiran ini, pada tanggal 29 November 1969 dan 18 Desember 1971 delegasi Republik Indonesia di Brussel menendatangani International Convention on Civil Liability for Oil Pollution Damage dan International Convention on the Establishment an International Fund for Compensation for Oil Pollution Damage, secara prinsip ketentuanketentuan tentang tanggung jawab pihak-pihak dalam hal terjadinya kecelakaan yang menyebabkan pencemaran laut akibat tumpahan minyak telah disetujui.

Indonesia dalam pelaksanaan lebih lanjut, melakukan ratifikasi melalui Keppres RI Nomor 18 Tahun 1969 tentang Pengesahan CLC 1969 
dan Keppres RI Nomor 19 Tahun 1978 tentang Pengesahan Konvensi Fund, pemberlakuan di Indonesia kemudian dicabut melalui Keppres Nomor 41 Tahun 1998. Selanjutnya Indonesia meratifikasi Protokol 1992 pada tahun 1999 dengan Keppres Nomor 52 tentang Pengesahan Protokol 1992 tentang Perubahan Terhadap Konvensi Internasional tentang Tanggung Jawab Perdata untuk Kerusakan Akibat Pencemaran Minyak 1969. Pencabutan tersebut berdasarkan penilaian Pemerintah Indonesia dalam posisinya sebagai Pihak dalam International Convention on the Establishment of an International Fund for Compensation for Oil Pollution Damage 1971 tidak efisien dan tidak ekonomis, sehingga dipandang perlu untuk mencabut Keputusan Presiden Nomor 19 Tahun 1978 tentang Pengesahan International Convention on the Establishment of an International Fund for Compensation for Oil PollutionDamage 1971.

Konvensi-konvensi

Internasional tersebut pada hakekatnya sebenarnya merupakan peralihan kewajiban dari pihak pelaku pencemar dalam hal ini kapal tanker (perusahaan kapal tanker/owner) kepada pihak ketiga untuk melaksanakan kewajibannya seturut dengan asas polluter pays polluter (asas pencemar berkewajiban membayar ganti kerugian terhadap pencemaran sebagai risiko dari aktivitasnya). Peralihan kewajiban membayar ganti kerugian ini dilaksanakan oleh pihak ketiga dalam hal ini asuransi yang sebelumnya telah diperjanjikan dan menjadi syarat dalam perjanjian pengangkutan kapal tanker. Kewajiban pembayaran ganti rugi pencemaran oleh pemilik kapal tanker yang diatur dalam konvensi internasional dilihat dari kepentingan para penggagasnya meliputi konvensi-konvensi hasil bentukan dari negara (IMCO/IMO) yang dibuat untuk menghindari kompleksitas hukum yang bisa timbul dalam kasus tumpahan minyak serta memenuhi kebutuhan regulasi internasional tentang kewajiban dan batasan ganti kerugian yang dapat dituntut oleh negara pantai sebagai korban pencemaran minyak oleh kapal tanker.

Regulasi Internasional dalam hal ini Konvensi tentang pertanggungjawaban dan kompensasi yang wajib dibayarkan oleh pelaku pencemar (tanker owners) membentuk dua rezim yang berlaku yaitu :

1. Rezim lama yang mendasarkan pada CLC 1969 dan Fund 1971;

2. Rezim baru yang mendasarkan pada CLC 1992 dan Fund 1992 beserta Supplementary Fund 2003.

3. Posisi Indonesia sebagai sebuah negara importir minyak, sudah meratifikasi CLC 1969 beserta amandemennya Protokol 1992, tanpa meratifikasi Fund Convention 1992 beserta Suplementary Fund 2003, dengan demikian posisi Indonesia sudah berada pada rezim baru pada tingkatan pertama kompensasi ganti rugi (primary tier). Rezim pertanggungjawaban dan kompensasi ganti kerugian yang dapat dituntut kepada pelaku pencemar minyak di laut Indonesia berdasarkan pada CLC 1992 mencapai 3 juta SDR ditambah perkalian sebesar 420 SDR (setara dengan US\$ 567) 
untuk setiap tambahan tonase untuk kapal dengan berat 5.000 sampai dengan 140.000 gross tonnage, dan 59,7 SDR (setara dengan 80 juta US\$) untuk kapal diatas 140.000 gross tonnage.

\section{Simpulan}

Kebutuhan akan ganti kerugian akibat pencemaran minyak kapal tanker direspon melalui Civil Liability for Oil Pollution Damage/CLC. CLC ini membentuk dua Rezim ganti rugi akibat pencemaran minyak oleh kapal tanker. Rezim lama berupa CLC 1969 dan Fund Convention 1971. Rezim lama dianggap tidak dapat memenuhi kompensasi ganti rugi dengan maksimal sehingga dibentuk rezim baru yang dikenal dengan tiga tingkatan kompensasi ganti kerugian pencemaran minyak oleh pemilik kapal (The three level of compensation established by the international convention). Tingkat pertama kompensasi mendasarkan pada CLC 1992. Tingkat kedua kompensasi mendasarkan pada Fund Convention 1992 dan Tingkat ketiga kompensasi mendasarkan pada Suplementery Fund 2003.

Posisi Indonesia dalam kompensasi ganti rugi pencemaran minyak dilaut oleh kapal tanker sudah berada pada rezim baru (new rezim), dengan CLC 1969 yang diratifikasi melalui Keppres RI Nomor 18 Tahun 1969 dan Protokol 1992 sebagai amandemen CLC 1969 dengan Keppres RI Nomor 52 Tahun 1999. Fund Convention 1971 yang semula diratifikasi oleh Indonesia melalui Keppres RI Nomor 19 Tahun 1978 tentang Pengesahan Konvensi Fund dicabut melalui Keppres Nomor 41 Tahun 1998. Pencabutan tersebut berdasarkan penilaian Pemerintah
Indonesia dalam posisinya sebagai Pihak dalam International Convention on the Establishment of an International Fund for Compensation for Oil Pollution Damage 1971 tidak efisien dan tidak ekonomis, sehingga dipandang perlu untuk mencabut Keputusan Presiden Nomor 19 Tahun 1978 tentang Pengesahan International Convention on the Establishment of an International Fund for Compensation for Oil PollutionDamage 1971. Keberadaan rezim baru kompensasi ganti rugi yang diterapkan di Indonesia diharapkan dapat memberikan ganti rugi maksimal bagi perlindungan lingkungan laut akibat pencemaran minyak oleh kapal tanker.

\section{Daftar Pustaka}

Batti, Pieter, 1995, Dasar-dasar Peraturan Keselamatan Pelayaran dan Pencegahan Pencemaran dari Kapal (sesuai IMO) Edisi Khusus, PT. Indo Asia.

Kusumaatmadja, Mochtar, 1976, IMCO dan Pembinaan Hukum Pelayaran Nasional, Majalah Padjajaran, Jilid VII, No. 1-2, Bandung.

Mochtar Kusumaatmadja, 1976, IMCO dan Pembinaan Hukum Pelayaran Nasional, Lembaga Penelitian Hukum dan Kriminologi, Fakultas Hukum Universitas Padjajaran, Binacipta, Bandung.

Rangkuti, Sundari, 2005, Hukum Lingkungan dan Kebijakan Lingkungan Nasional, Edisi ketiga, Airlangga University Press, Surabaya.

Sands, Phillipe, 2003, Principles of International Environmental Law, Second Edition, 
Cambridge University Press, United Kingdom.

United Nations Conference on Trade and Development, 2012, Liability and Compensation for Ship-Source Oil Pollution : An Overview of the International Legal Framework for Oil Pollution Damage from Tankers, Studies in Transport Law and Policy, No. 12012.

Krishna Kiran, R. Bhanu, OctoberDesember 2010, Liability and Compensation for Oil

Pollution Damage: An

Examination of IMO

Conventions.

Sumampouw, M., 1980, Hague-Zagreb Essays 3, Carriage of Goods by Sea et. Al., Hague.

Peraturan Presiden Nomor 65 Tahun 2014 Tentang Pengesahan Convention on Civil Liability for Bunker Oil Pollution Damage, 2001 (Konvensi Internasional mengenai Tanggung Jawab Sipil Terhadap Kerusakan Akibat Pencemaran Minyak Bahan Bakar, 2001)

Keputusan Presiden Republik Indonesia Nomor 18 Tahun 1978 Tentang Pengesahan International Civil Liabiality for Oil Pollution Damage 1969.

Keputusan Presiden Republik Indonesia Nomor 52 Tahun 1999 Tentang Pengesahan Protocol of 1992 to Amend the International Convention on Civil Liability for Oil Pollution Damage 1969 (Protokol 1992 Tentang Perubahan Terhadap Konvensi
Internasional Tentang Tanggung Jawab Perdata Untuk Kerusakan Akibat Pencemaran Minyak 1969).

1969 Tankers Owners Voluntary Agreement on Liability for Oil Pollution (TOVALOP), 8 ILM $497 \quad$ (1969) (ceased operation 20 February 1997).

1971 Contract Regarding an Interim Settlement of Tanker Liability for oil Pollution (CRISTAL), 10 ILM 137 (1971) (ceased operation 20 February 1997).

1971 International Convention on the Establishment of an International Fund for Compensation for Oil Pollution Damage (1971 Fund Convention).

1982 United Nations Convention on the Law of the Sea (UNCLOS).

1992 Protocol to the International Convention on Civil Liability for Oil Pollution Damage 1969(the Consolidated Text as Amanded by the 1992 Protocol is Referred to as CLC 92).

1992 Fund for Compensation for Oil Pollution Damage 1971 (the Consolidated Text as Amended by the 1992 Protocol is referred to as 1992 Fund Convention).

2001 International Convention on Civil Liability for Bunker Oil pollution Damage 2001 (Bunker Convention).

2003 The 2003 Protocol Establishing an International Oil Pollution Compensation Supplementary Fund.

2006 Small Tanker Oil Pollution Indemnification Agreement (STOPIA) 
2006 Tanker Oil Pollution Indemnification Agreement (TOPIA)

Http://www.imo.org/imo/convent/s ummary.htm, IMOs Web Site Summary of Status of Convention.

Http://www.imo.org/imo/conventio $\mathrm{n} /$ index.htm, IMO-index of convention, 18 Februari 2013. Http://www.imo.org/imo/convent/s ummary.htm, IMOs Web Site- summary of Status of

Convention.

Http://www.amsa.gov.an/me/pn324.

htm, Marine Pollution Legislation.

Http://www.amsa

.gov.an/me/pn324.htm,

Marine Pollution Legislation.

www.imo.org Information on

Contracting States based on

IMO; SDR exchange rate based on (www.imf.org).

Www.iopcfunds.org. 